\title{
Relationship between severity of migraine and sympathetic skin response in migraine patients during inter ictal period: Case control study
}

\author{
Ramesh Kannan $\mathbf{S}^{1}$, Sathiyamoorthy $\mathbf{P}^{2, *}$, Ariarathinam Newtonraj ${ }^{3}$, Subhasis Das ${ }^{4}$ \\ ${ }^{1}$ Associate Professor, ${ }^{2,3}$ Assistant Professor, ${ }^{4}$ Professor \& HOD, ${ }^{1}$ Dept. of Neurology, ${ }^{2,4}$ Dept. of Physiology, ${ }^{3}$ Dept. of \\ Community Medicine, Pondicherry Institute of Medical Sciences, Pondicherry, India
}

\section{*Corresponding Author:}

Email: sathiyacmo@gmail.com

\begin{abstract}
Introduction: Migraine is a neurovascular disorder associated with sympathetic and parasympathetic hypofunction, hyperfunction or sympathetic instability, affecting all age groups, predominantly women between 14-45 years of age group. Our objective was to determine the relationship of severity of migraine and sympathetic skin response and to compare the sympathetic skin responses of migraine patients and those with non specific complaints.

Material and Methods: This study was conducted in a tertiary care medical college hospital in Pondicherry. Migraine patients (cases) were selected based on International Headache Society criteria for diagnosis of migraine without aura. Controls were the individuals in the same age group who attended the Neurology outpatient department with nonspecific complaints other than headache. Total sample size was 72 (36 patients with migraine and 36 controls). Data were collected using a pretested questionnaire. Sympathetic skin response was obtained from both upper and lower limbs, assessed in terms of latency and amplitude among patients with migraine and controls.

Results: The latencies of both upper and lower limbs were significantly increased in migraine patients than controls $(\mathrm{p}<0.01)$.There was no significant difference in the amplitude between the two groups. We also determined the relationship between the severity of migraine with sympathetic skin response and found that Migraine patients with mild pain had no significant differences in the latency and amplitude; whereas, Migraine patients with moderate and severe pain had significantly increased latencies in both Upper and Lower Limbs $(\mathrm{p}<0.05)$.

Conclusion: Patients with moderate and severe migraine had significantly longer latencies than controls which suggests sympathetic hypofunction during headache free period.
\end{abstract}

Keywords: Sympathetic skin response (SSR), Migraine, Case control study, Migraine severity.

\section{Introduction}

Migraine is the most common type of headache affecting daily activities and emotional status of the individual who has it. It is considered to be a primary neural process. ${ }^{1,2}$ Aura in migraine and activation of trigeminovascular system is found to be caused by neuronal depolarization involving the occipital cortex, limbic system and the brainstem with internal and external triggers in a highly excitable cerebral cortex and the depression wave. ${ }^{3}$

Migraine is a neurovascular disorder affecting all age groups, predominantly women between $14-45$ years of age group. The underlying cause of migraine is not known. Neurogenic inflammation is considered as one of the factors in the pathophysiology of migraine. Calcitonin gene related peptide and serotonin have been related to the pain in migraine. It has been reported that migraine has been associated with sympathetic and parasympathetic hypofunction, ${ }^{4,5}$ hyperfunction ${ }^{6,7}$ or sympathetic instability. ${ }^{8,9}$ Examination of sympathetic skin response has been recorded from the hand, soles, superior ophthalmic nerve stimulation with soap or salt eye drops, pupil functions, thermographic asymmetry, heart rate variables, frontal blood flow measurement has been performed to investigate sympathetic dysfunction in migraine.
It was decided to conduct a study to determine the relationship of migraine severity and sympathetic skin response in migraine patients, which is yet to be explored and to compare the sympathetic skin response in migraine patients with those with non specific complaints.

\section{Material and Methods}

Methods: This study was conducted from January 2018 to April 2018 in a tertiary care medical college hospital in Pondicherry.

Data Collection: Participants information sheet were distributed among the participants. Informed consent was obtained.Migraine patients were selected based on International Headache Society (IHS) criteria for diagnosis of migraine without aura. ${ }^{10}$

\section{IHS Criteria for diagnosing migraine without aura}

A. At least five attacks fulfilling B-D

B. Attacks lasting 4-72 hours if untreated or unsuccessfully treated

C. Headache has at least two of the following characteristics
a. Unilateral location
b. Pulsating quality
c. Moderate or severe pain intensity
d. Aggravation by or causing avoidance of routine physical activity 
D. During headache, at least one of the following

a. Nausea and / or vomiting

b. Photophobia / Phonophobia

E. Headache not attributable to any other disorder

Controls were the individuals with non specific complaints like pain, aches, muscle stiffness etc. of the same age group who attended the outpatient department. We included patients with age group between 18- 50 years, both male and female migraine patients without co morbidities.Patients with cardiovascular, renal or central nervous system disorder, cluster headache, tension headache, other CNS causes of headache, patients with pacemaker, Migraine patients on beta blockers were excluded from the study. Controls were selected with no comorbidities. Sample size was calculated using Open epi Version 3.01 based on one of the previous study. ${ }^{11}$ Total sample size calculated was 72 (36 patients with migraine and 36 controls). Cases and controls were selected using consecutive sampling method to avoid bias. Frequency matching of cases with controls was done in age group with \pm 5 years. Data was collected using a pretested questionnaire. Numerical pain rating scale was used to categorize the migraine patients to mild, moderate and severe ${ }^{12}$.Sympathetic skin response was done using EMG machine, an instrument with power lab data acquisition unit (version 81.3 01-032016) with lab chart 8 software was used for the study.Power lab $26 \mathrm{t}$ with 8 channel bio amplifier with a ML 4085 channel amplifier cable to connect to ECG electrodes was used. Data were entered and analysed using Epidata software (Epidata v 3.1 for Entry and v 2.2.2.182 for analysis, EpiData Association, Odense, Denmark-. Difference in the means of amplitude and latency was compared using independent $\mathrm{T}$ test.

Migraine patients and the controls were asked to report to the physiology research laboratory between 9 $\mathrm{AM}$ and 10AM after a light breakfast. They were asked to bring their serum TSH and HbA1C reports. Patient's detailed medical history, demographic details, and basal vital parameters were noted. Skin temperature was recorded in the non dominant hand with a digital thermometer placed over the skin of a forearm. An active surface electrode was placed on the palmar area and the reference electrode was placed on the dorsal aspect of the same arm and the ground anywhere on the ventral aspect of the forearm. Similarly, in the lower limb also, an active recording electrode was placed on the soles and the reference electrodes was placed on the dorsum of feet. ECG electrodes were placed on either side of the nares to record EMG(Electromyography).

After the placement of electrodes subjects were asked to relax for 10 to 15 minutes in the supine position.SSR was recorded in the supine position after a deep inspiration using a sweep speed of $20 \mathrm{~mm} / \mathrm{sec}$. The latency of SSR was calculated by the time lag in seconds between the onset of EMG of nares and the onset of SSR waveform.The amplitude of SSR was given by the peak to peak distance between the positive and negative waves of SSR. ${ }^{12}$

Ethical committee approval was obtained from institute ethical committee. (Institutional ethical committee approval no: $\mathrm{RC} / 17 / 55$ )

\section{Results}

36 patients with migraine and 36 controls were studied. Characteristics of the patients are given in the table 1. Mean difference in terms of limb latency and amplitude are presented in table 2. Patients with Migraine had significantly higher limb latency compared to controls (upper limb: controls [1.2(0.4):], migraine $[2.0(0.4):], \mathrm{p}<0.01)$. However, patients with mild category of migraine did not significantly differ from the mean latency of controls. Limb amplitudes were found to be similar across all sub groups of migraine and controls. (Table 2)

Table 1: Characteristics of the study participants

\begin{tabular}{|l|l|c|c|c|}
\hline \multicolumn{2}{|c|}{ Variables } & Cases & Controls & p value $^{\#}$ \\
\hline Gender $^{\$}$ & Male & $14(39)$ & $22(61)$ & 0.06 \\
\hline & Female & $22(61)$ & $14(39)$ & \\
\hline Religion & Hindu & $27(48)$ & $29(52)$ & 0.7 \\
\hline & Muslim & $3(50)$. & $3(50)$ & \\
\hline Marital Status $^{\$}$ & Christian & $6(60)$ & $4(40)$ & \\
\hline & Married & $22(45)$ & $27(55)$ & 0.2 \\
\hline Education $^{\$}$ & Upmarried & $14(60)$ & $9(39)$ & \\
\hline & Others & $9(41)$ & $13(59)$ & 0.7 \\
\hline Occupation $^{\$}$ & Home maker & $25(52)$ & $23(48)$ & \\
\hline & Others & $25(48)$ & $27(52)$ & \\
\hline $\begin{array}{l}\text { Age (yrs) } \\
\text { mean (SD) }\end{array}$ & & $32.0(12.6)$ & $35.1(12.9)$ & 0.3 \\
\hline SBP (mmHg) & & 122.3 & 121.1 & 0.7 \\
\hline
\end{tabular}




\begin{tabular}{|l|c|c|c|c|}
\hline mean (SD) & & $(12.6)$ & $(14.7)$ & \\
\hline $\begin{array}{l}\text { DBP(mmHg) } \\
\text { mean (SD) }\end{array}$ & $77.2(11.0)$ & $75.7(9.9)$ & 0.5 \\
\hline $\begin{array}{l}\text { Weight (kgs) } \\
\text { mean (SD) }\end{array}$ & & $57.6(11.0)$ & $61.1(13.6)$ & 0.2 \\
\hline $\begin{array}{l}\text { Height (cms) } \\
\text { mean (SD) }\end{array}$ & $153.1(8.7)$ & $\begin{array}{c}152.2 \\
(15.7)\end{array}$ & 0.5 \\
\hline $\begin{array}{l}\text { HbA1C (\%) } \\
\text { mean (SD) }\end{array}$ & Up to 3 & $5.3(0.3)$ & $5.4(0.8)$ & 0.8 \\
\hline TSH $^{\text {S }}$ & $>3$ & $6(35)$ & $11(65)$ & 0.1 \\
\hline
\end{tabular}

*SBP- Systolic blood pressure, DBP- Diastolic blood pressure, SD-Standard Deviation, $\$$ proportions expressed in $\mathrm{n}$ (\%), \# Chi-square for proportions and $\mathrm{T}$ test for mean

Table 2: Mean difference between cases and controls in terms of limb latency and amplitude

\begin{tabular}{|l|c|c|c|c|c|c|c|c|}
\hline & \multicolumn{2}{|c|}{ UL Latency } & \multicolumn{2}{c|}{ UL Amplitude } & \multicolumn{2}{c|}{ LL Latency } & \multicolumn{2}{c|}{ LL Amplitude } \\
\hline & $\begin{array}{c}\text { Mean } \\
\text { (SD) }\end{array}$ & p value* & $\begin{array}{c}\text { Mean } \\
\text { (SD) }\end{array}$ & p value* & $\begin{array}{c}\text { Mean } \\
\text { (SD) }\end{array}$ & p value* & $\begin{array}{c}\text { Mean } \\
\text { (SD) }\end{array}$ & p value* \\
\hline $\begin{array}{l}\text { Controls } \\
\mathrm{n}=36\end{array}$ & $1.2(0.4)$ & -- & $1.4(1.3)$ & -- & $1.4(0.8)$ & -- & $1.1(0.8)$ & -- \\
\hline $\begin{array}{l}\text { Cases } \\
\mathrm{n}=36\end{array}$ & $2.0(1.4)$ & $<0.01$ & $1.4(0.8)$ & 0.9 & $2.1(0.9)$ & $<0.01$ & $1.3(0.7)$ & 0.3 \\
\hline $\begin{array}{l}\text { Mild } \\
\mathrm{n}=4\end{array}$ & $1.4(1.4)$ & 0.5 & $0.9(0.7)$ & 0.5 & $1.9(0.6)$ & 0.08 & $1.4(0.4)$ & 0.5 \\
\hline $\begin{array}{l}\text { Moderat } \\
\text { e n=17 }\end{array}$ & $1.7(1.1)$ & 0.03 & $1.4(0.9)$ & 0.9 & $1.8(0.8)$ & 0.04 & $1.1(0.7)$ & 0.9 \\
\hline $\begin{array}{l}\text { Severe } \\
\mathrm{n}=15\end{array}$ & $2.6(1.6)$ & $<0.01$ & $1.6(0.8)$ & 0.5 & $2.5(1.0)$ & $<0.01$ & $1.5(0.8)$ & 0.1 \\
\hline
\end{tabular}

*p value on comparing with control

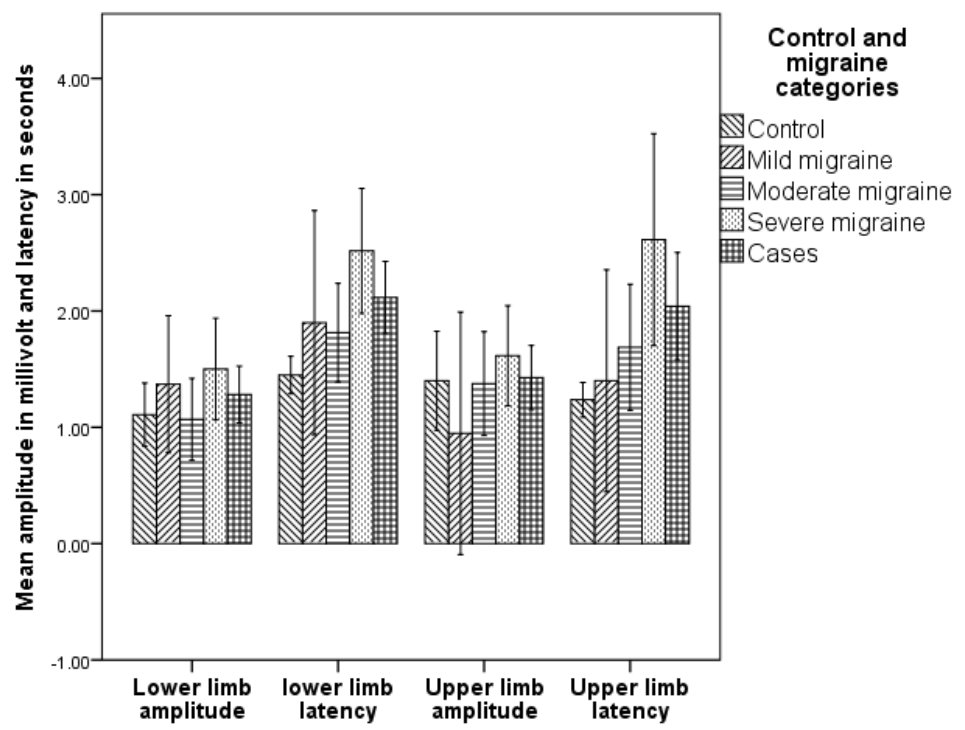

Fig. 1: Mean amplitude and latency in upper and lower limb in different categories with $95 \%$ confidence interval error bar

\section{Discussion}

Sympathetic skin response (SSR) is a non invasive procedure done for the assessment of sympathetic nervous system function. SSR is due to synchronised activation of sweat glands in response to volley of discharges by efferent sympathetic nerve fibres.
We identified from this study that SSR latencies were significantly prolonged in migraine patients (cases) than controls and also there was no statistically significant difference in the SSR amplitude between the two groups. 
We also determined the relationship between the severity of migraine with SSR and found that Migraine patients with mild patients with mild pain had no significant differences in the latency and amplitude, whereas migraine patients with moderate and severe pain had significantly prolonged latencies.

The above findings were found to be similar in a study conducted by Atosy et al., that Sympathetic skin response latencies in patients with medication overuse headache and in migraineurs were significantly longer than in controls. ${ }^{13}$

In a study conducted by Torun et al, it was found that, there was neither a significant difference in R-R interval variation (RRIV) and SSR between migraine and control groups ( $>0.05)$ nor in heart rate responses to deep breathing $(\mathrm{p}=0.83)$. The mean amplitude of SSR in children with migraine was smaller than that in the control group, but it did not reach a level of statistical significance. ${ }^{14}$

Yildis et al. reported changes in the amplitude and latency of SSR during the interictal period of migraine pointing towards sympathetic hypofunction..$^{15}$ Avnon et al. concluded that intracranial sympathetic and parasympathetic vascular changes are related to the migraine symptomatology and pathophysiology. ${ }^{16}$ Aysel et al has found thatmigraine patients showed significantly longer latencies in the patients than controls similar to our results. ${ }^{17}$ Drummond demonstrated that the patients with unilateral migraine showed sympathetic hypo-function during the attacks. ${ }^{18}$ In our study, patients with moderate and severe migraine had prolonged latencies during the interictal period suggesting sympathetic hypofunction. Bektas et al. demonstrated that a more evident sympathetic hypofunction occurred during the headache. ${ }^{19}$

It has been reported that SSR amplitude which is obtained from homologous regions of two sides of the body were found to be similar, this is due to same physiologic and anatomic factors contributing to them. ${ }^{20-24}$ Several studies showed that the average of the largest amplitude responses and mean of shortest SSR latencies have been considered for those participants whose SSR was not recordable in single stimulus. ${ }^{25,26}$ In this study SSR was recordable in all the control and migraine patients and was no non-responder. A single stimulus was used to record both latencies and amplitude.

We decided to use sympathetic skin response to assess the autonomic nervous system function due to the pleasant and cost effective nature of the test when compared to other tests like Valsalva manoeuvre, deep breathing, isometric hand grip test, Cold pressor test, Mental arithmetic test, Active standing (orhthostatic) test, Head-up tilt test and baro reflex sensitivity testing. ${ }^{27}$

Implication of the study: None of the previous studies have compared the relationship of severity of migraine with sympathetic skin response to identify the changes in autonomic nervous system function.

Limitation of the study: Single hospital based study

\section{Conclusion}

Patients with moderate and severe Migraine have significantly prolonged latencies than controls, suggesting sympathetic hypofunction during the headache free period.

\section{References}

1. Lewis DW. Toward the definition of childhood migraine. Curr Opin Pediatr 2004;16:628-36.

2. Silberstein S. Migraine. Lancet 2004;31:381-91.

3. Meyer JS, Hata T, Imai A, Zetuksky WJ. Migren and intcranial swelling. Lancet 1985;7:1308-09.

4. Peroutka SJ. Migraine: A chronic sympathetic nervous system disorder. Headache 2004;44:53-64.

5. Mylius V, Braune HJ, Schepelmann K. Dysfunction of the pupillary light reflex following migraine headache. Clin Auton Res 2003;13:16-21.

6. Micieli G, Tassorelli C, Magri M, Sandrini G, Cavallini A, Nappi G. Vegetative imbalance in migraine. A dynamic TV pupillometric evaluation. Funct Neurol 1989;4:105-111.

7. Cortelli P, Pierangeli G, Parchi P, Contin M, Baruzzi A, Lugaresi E. Autonomic nervous system function in migraine without aura. Headache 1991;31:457-462.

8. Appel S, Kuritzky A, Zahavi I, Zigelman M, Akselrod S. Evidence for instability of the autonomic nervous system in patients with migraine. Headache 1992;32:10-17.

9. Zigelman M, Kuritzky A, Appel S, Davidovitch S, Zahavi I, Hering R, Akselrod S. Propranolol in the prophylaxis of migraine-evaluation by spectral analysis of beat-tobeat heart rate fluctuations. Headache 1992;32:169-174.

10. Francis. Migraine without aura- towards a new definition. J Headache Pain Mgmt 2016;1(2):8.

11. Misra UK, Kalita J. Textbook Clin Neurophysiol 2001:105.

12. Jensen A, Sorensen MR, Karshenas A, Bach FW, Cairns BE, Arendt- Nielsen L et al. Mechanical sensitivity in migraine patients during attack, remission, and pain- free periods: A preliminary study. Scand J Pain 2017;3(3):194.

13. Atasoy HT, Atasoy N, Unal AE, Sumer M. Sympathetic skin response in migraineurs and patients with medication overuse headache. Headache United States; 2004;44(4):305-10.

14. Torun E, Guler S. Characteristic Features of Migraine in Schoolchildren and Adolescents and Its Relationship with Autonomic Nervous System Disorders 2013;252-6.

15. Yildiz SK, Yildiz N, Korkmaz B, Altunrende B, Gezici AR, Alkoy S. Sympathetic skin responses from frontal region in migraine headache: A pilot study. Cephalalgia 2008;28(7):696-704.

16. Avnon Y, Nitzan M, Sprecher E, Rogowski Z, Yarnitsky D. Autonomic asymmetry in migraine: Augmented parasympathetic activation in left unilateral migraineurs. Brain 2004;127(9):2099-108.

17. Aysel,Temel tombul,Refah Sayin.sympathetic skin responses in migraineurs. J Clin Experi Investigations 2011;2(1):116-21.

18. Drummond PD. Pupil diameter in migraine and tension headache. J Neurol Neurosurg Psychiatry 1987;50:22830 . 
19. Korkmaz B, Yildiz S, Yildiz N. Sympathetic Skin Responses from the Neck Area in Patients with Unilateral Migraine. Nöro Psikiyatri Arşivi 2015;52(2):151-6.

20. Yildiz SK, Turkoglu SA, Yildiz, Ozturk A, Tore F.Sympathetic skin responses of the face and neck evoked by electrical stimulation. Auton Neurosci 2007;134:85-91.

21. Bonanno PC, Palaia D, Rosenberg M, Casson P. Prophylaxis against Frey's syndrome in parotid surgery. Ann Plast Surg 2000;4:498-501.

22. Matsutani K,Tsurupka M, Shinya A, Furuya R, Kawawa T. Stimulation of the locus coeruleussupresses trigeminal sensorimotor function in the rat. Brain Res Bull 2005;53:827-32.

23. Sasa M, Fujimoto S, Igarashi S, Munekiyo K, Takaori S. Microiontophoretic studies on noradrenergic inhibition from locus coeruleus of the spinal trigeminal nucleus neurons. J Pharmacol Exp Ther 1979;210:311-15.

24. Gruzelier JH, Nicolaou T, Connolly JF, Peatfield RC, Davies PT, Clifford-Rose F. Laterality of pain in migraine distinguished by interictal rates of habituation of electrodermal responses to visual and auditory stimuli. $J$ Neurol Neurosurg Psychiatry 1987;50:416-422.

25. Marcelo M, Nogues M, Leiguarda R, Saubidet CL, Florin A. Abnormal sympathetic skin response in patients with autoimmune vitiligo and primary autoimmune hypothyroidism. J Neurol 1993;240:72-4.

26. Shahani B, Halperin JJ, Boulu P, Cohen J. Sympathetic skin response-a method of assessing unmyelinated axons dysfunctions in peripheral neuropathies. J Neurol Neurosurg Psychiatric 1984;47:536-42.

27. Zygmunt A, Stanczyk J. Methods of evaluation of autonomic nervous system function. Arch Med Sci 2010;6(1):11-8. 